\title{
Caleidoscopio del cuerpo: Entre imaginarios y narrativas de la diversidad corporal ${ }^{1}$
}

Body kaleidoscope: Between imaginary and narratives of body diversity // Caleidoscópio corpo: Entre imaginário e narrativas da diversidade corporal

Luisa Fernanda González Peña ${ }^{2}$

Escuela Nacional de Antropología e Historia, ENAH, México

oceloth_51@hotmail.com

Revista Corpo-grafías: Estudios críticos de y desde los cuerpos / Volumen 7 Número 7 / Enero - diciembre 2020 / ISSN impreso 2390-0288, ISSN digital 25909398 / Bogotá, D.C., Colombia / 161-174

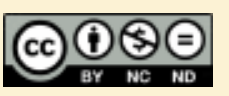

Fecha de recepción: 16 de enero de 2019

Fecha de aceptación: 3 de mayo de 2019

DOI: https://doi.org/10.14483/25909398.15513

Cómo citar este artículo: González Peña, L. F. (2020, enero-diciembre). Caleidoscopio del cuerpo: Entre imaginarios y narrativas de la diversidad corporal. Revista Corpo-grafías: Estudios críticos de y desde los cuerpos, 7(7), pp. 161-174 / ISSN 2390-0288.

Articulo de Investigación: Este artículo forma parte de la Investigación "Caleidoscopio del cuerpo: Entre imaginarios y narrativas de la diversidad corporal" que se realiza gracias al apoyo del Consejo Nacional de Ciencia y Tecnología CONACyT. 2 Dentista cirujana, egresada de FES Iztacala UNAM. Licenciada y Maestra en Antropología Física, egresada de la Escuela Nacional de Antropología e Historia. Actualmente, estudiante de Doctorado en Antropología Física de la ENAH. 


\section{Resumen}

El presente artículo se enfocará en dos grupos de estudio poseedores de condiciones médicas que modifican su estructura corporal: la acondroplasia y acromegalia (enfermedad congénita y adquirida). Existe un contraste en dichas condiciones médicas; sin embargo, ambas han servido a lo largo del tiempo para resaltar las diferencias corporales ante el espectador que capta estas imágenes en un instante o de manera contemplativa. Podemos exponer que los ojos nos crean una realidad, mientras la conciencia y la imagen corporal se construyen desde varias miradas incluyendo la de los otros. La única manera de comprender este tipo de hibridaciones y su importancia es examinar con atención las imágenes y describir el vocabulario de sus formas. Se abordan estos grupos de estudio desde la experiencia y el imaginario social, partiendo del análisis semiótico-discursivo como herramienta metodológica.

\section{Palabras clave}

Acromegalia; acondroplasia; semiótica; diversidad corporal; cuerpo

\section{Abstract}

This article will focus on two study groups with medical conditions that modify their body structure: achondroplasia and acromegaly (congenital and acquired disease). There is a contrast in these medical conditions; however, both have served over time to highlight the bodily differences before the viewer that captures these images in an instant or in a contemplative way. We can expose that the eyes create a reality to us, while the conscience and the corporal image are constructed from several looks including the one of the others. The only way to understand this type of hybridization and its importance is to examine the images carefully and describe the vocabulary of their forms. These study groups are approached from the experience and the social imaginary, starting from the semiotic-discursive analysis as a methodological tool.

\section{Keywords}

Acromegaly; achondroplasia; semiotics; body diversity; body

\section{Resumo}

Este artigo enfoca dois grupos de estudo com condições médicas que modificam sua estrutura corporal: acondroplasia e acromegalia (doença congênita e adquirida). Há um contraste nessas condições médicas; no entanto, ambos serviram ao longo do tempo para destacar as diferenças corporais diante do espectador que capturam essas imagens em um instante ou de forma contemplativa. Podemos expor que os olhos nos criam uma realidade, enquanto a consciência e a imagem corporal são construídas a partir de vários olhares incluindo os dos demais. A única maneira de entender esse tipo de hibridização e sua importância é examinar cuidadosamente as imagens e descrever o vocabulário de suas formas. Esses grupos de estudo são abordados a partir da experiência e do imaginário social, a partir da análise semiótico-discursiva como ferramenta metodológica.

\section{Palavras-chave}

Acromegalia; acondroplasia; semiótica; diversidade corporal; corpo

\section{Introducción}

Comenzaré con una descripción breve de las dos condiciones para conocer sus manifestaciones corporales y algunos de sus síntomas: La acromegalia ${ }^{3}$ es una enfermedad crónica silenciosa que se presenta en personas de edad mediana (30 a 50 años), causada por una secreción excesiva de la hormona de crecimiento, la cual es producida en la glándula pituitaria, ${ }^{4}$ generalmente, el

3 Formado por las raíces griegas akro- к-/äkpo gr. "extremo", "punta" + -megalia $\mu \varepsilon \gamma \alpha \lambda$-ía gr. cient. "tamaño excesivo".

$4 \quad$ La hipófisis o glándula pituitaria es una glándula endocrina que segrega hormonas encargadas de regular la homeostasis incluyendo las hormonas trópicas que regulan la función de otras glán- 
aumento de la hormona de crecimiento se relaciona con el desarrollo de un tumor benigno. En el país son alrededor de 5.000 a 6.000 personas y solamente 1.500 están diagnosticados (Arellano, et al., 2004).

Los principales signos y síntomas son facciones toscas a medida que los huesos crecen, crecimiento anormal de manos y pies y encorvamiento de la columna vertebral; voz grave, engrosamiento de las costillas (dando forma de barril al pecho), dolor de cabeza, pérdida de la visión, debilidad y cansancio. Una característica relevante de esta enfermedad es que dichos cambios se manifiestan en forma lenta y progresiva en el transcurso de cinco a diez años (González, 2012).

La acondroplasia ${ }^{5}$ es una enfermedad de tipo congénito, que afecta al desarrollo del cartílago de conjunción de los huesos largos, produciendo un crecimiento disarmónico del cuerpo. Aunque existen 250 displasias óseas que generan talla baja, se estima que la acondroplasia representa el $15 \%$ del conjunto de displasias esqueléticas conocidas. Horton y colaboradores (2007), estiman que existen en el mundo unas 250 mil personas afectadas. En nuestro país esta condición afecta a una persona por cada 23.000.

En el proceso de crecimiento y desarrollo normal, los tejidos cartilaginosos son sustituidos por hueso durante el desarrollo fetal y la niñez, a excepción de la nariz y las orejas. Las personas con esta condición presentan miembros superiores e inferiores muy cortos en relación con su tronco, el cual tiene dimensiones normales. La cabeza

dulas del sistema endocrino, dependiendo en parte del hipotálamo el cual a su vez regula la secreción de algunas hormonas. Es una glándula compleja que se aloja en un espacio óseo llamado silla turca del hueso esfenoides, situada en la base del cráneo, en la fosa cerebral media, que conecta con el hipotálamo a través del tallo pituitario o tallo hipofisario.

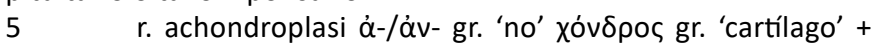
$-\pi \lambda \alpha \sigma i \alpha$ gr. cient. 'formación celular' es relativamente grande en relación con el tronco, siendo la forma del cráneo una de las características anatómicas más peculiares debido a su gran tamaño (macrocefalia), la frente abombada, aplanamiento de la parte media de la cara y la raíz nasal (González, 2014).

El cuerpo abordado desde tiempos antiguos ha portado distintas definiciones y concepciones, representaciones y verbalizaciones en diversos ángulos. Dejando abierta una infinita combinación y variaciones acerca de su concepción. Diversos autores han definido este elemento tan escurridizo y camaleónico llamado cuerpo.

Raymundo Mier, reflexiona acerca del cuerpo y su importancia a través del tiempo y las formas de abordarlo generando múltiples puntos de vista, experiencias, saberes, así como el objeto de procesos de reconocimiento, aprehensión de la propia identidad y de la identidad de los otros:

El cuerpo ha aparecido, en todos los momentos de la cultura, a un tiempo como vértice y punto de referencia de la reflexión. Apertura para la comprensión del mundo y, simultáneamente, como enigma, opacidad. Como origen de lo visible y agente de toda visibilidad, pero también como objeto destinado a la exploración, la descripción. (Mier, 2009, p. 11).

Partiendo de esta reflexión se considera al cuerpo como el eje rector de nuestras acciones, una máquina del tiempo, una fábrica de recuerdos, un mapa de vida, un territorio; una condición simbólica irremplazable para la experiencia de la contemporaneidad.

La experiencia de la corporalidad se muestra como la expresión de un conjunto de genealogías: las genealogías del cuerpo biológico, distintas de aquellas del cuerpo perceptual, o del cuerpo que emerge del encuentro con el otro y el juego de reconocimiento, como matiz 
de significación, o como lugar de las sensaciones, de las pulsiones, de las afecciones, la consolidación de efigies y destinos de la identificación o la melancolía; el cuerpo como genealogía de escenificaciones y como revelación de supremacías y de potencias diferenciadas; como génesis de las vicisitudes del género y las fisionomías de la sexualidad, el cuerpo como síntesis disyuntiva de esta ocurrencia de regímenes genealógicos. (Mier, 2009, p.13).

Dichas aproximaciones han colocado al cuerpo en un caleidoscopio que genera una difracción multicolor construyendo diferentes perspectivas de abordaje a partir de este filtro antropológico. El pensamiento disciplinario es simplificador y no nos permite abordar el objeto de estudio a partir de su multidimensionalidad. En cada investigación se delimita el tema para explicar determinado fenómeno; sin embargo, forma parte de dicho entramado y ofrece un panorama parcial que no significa tener que cercenar y mutilar al evento en sí.

La más mínima parte del sujeto o fenómeno contiene sistemas complejos que no pueden ser eliminados; así como la búsqueda de plantear un método y un principio de conocimiento que no permita bloqueos. De esta manera, Morin, propone el paradigma de la complejidad:

La complejidad no elimina la simplicidad no debe confundirse complejidad con completud, esta debe concebirse como un conocimiento multidimensional que articula campos disciplinarios que anteriormente se encontraban separados (Morin, 1996).

Se abordará solo una forma de producción visual por cuestión de espacio para abordar la construcción semiótico-dircursiva de los grupos de estudio; aplicando modelos de teóricos importantes del campo de la semiótica visual y el discurso como Roland Barthes, Iuri Lotman, Catalá, y Julieta Haidar.

\section{El uso de la semiótica y el discurso para el análisis del cuerpo}

Retomando el concepto de cuerpo considerado como un organismo vivo constituido por una estructura físico-simbólica, capaz de producir y reproducir significados. Un proceso de producción de sentido que implica una interacción continua del sujeto con otros cuerpos dentro de un tiempo-espacio determinado. Este proceso de simbolización corporal se relaciona íntimamente con el contexto histórico-socio-cultural y el universo ideológico particular, por ello el concepto de cuerpo sintetiza la comprensión del universo de una cultura. (Aguado, 2004, p.25).

Si vemos un texto como si fuera un tejido colmado de significados, el cuerpo también es uno de ellos, que, a comparación del anterior, se encuentra en continua construcción. Para Lotman, abarca tanto el discurso verbal, como todas las producciones semióticas que establece observar a la cultura como semiósfera. En ese sentido, todo fenómeno constituye un texto (moda, culinaria, espacio, objetos, ritos, música, entre otros) que permite abandonar la idea tradicional de lo escrito-literario y ampliar productivamente su uso. De este modo, se sirve considerar algunas premisas principales:

- Es un dispositivo de la memoria de la cultura

- Es un generador de sentido

- Es heterogéneo, políglota

- Es un soporte, productor y reproductor de lo simbólico

- Constituye un campo del cambio cultural (Haidar, 2006, p. 74)

Barragán propone utilizar de manera complementaria, herramientas teórico-metodológicas en semiótica de la cultura con objetivo de generar una antropología interpretativa para el campo antropofísico y ofrecer lectura a las metáforas del cuerpo, tomando como referente la 
antropología simbólica de Geertz y su concepto de cultura que "denota un esquema históricamente transmitido de significaciones representadas en símbolo, un sistema de concepciones heredadas y expresadas en formas simbólicas por medio de los cuales los hombres comunican, perpetúan y desarrollan sus conocimiento y sus actitudes frente a la vida" (Geertz, 1992, p. 88).

Se considera a la cultura como un sistema de comunicación y la antropología y la lingüística dos disciplinas que se influyen mutuamente (Barragán, 2011, p. 364). Para conocer dicha construcción, Haidar destaca la importancia de la semiótica de la cultura y el análisis del discurso como: Instrumentos teórico-metodológicos fundamentales para la comprensión del funcionamiento de lo político, lo cultural, lo social, lo histórico y lo ideológico en las distintas prácticas semiótico-discursivas, y que permiten dar cuenta de la complejidad analítica de los sujetos de estudio en su mundo contemporáneo.

Desde esta perspectiva, tales prácticas contienen materialidades y funcionamientos peculiares que inciden de manera determinante para la producción y reproducción de la vida socio-histórico-político-cultural de los sujetos. La relación entre las prácticas discursivas y las otras prácticas sociales; la construcción de una teoría del sujeto desde una perspectiva inter y transdisciplinaria (Haidar, 2006, pp.18-46).

Sin embargo, no todo se encuentra en el discurso, Haidar resalta la importancia de la semiótica y en específico el aspecto visual, lo más productivo en cuanto a sistemas y prácticas visuales, como en teorías y análisis de lo visual, esto se debe a dos razones. En las diferentes etapas históricas de todas las culturas, lo verbal y lo visual no se separan, siempre tienen una relación orgánica constitutiva: de los dos órganos sensoriales, los más productivos para la producción semiótica son los oídos y los ojos. En segundo lugar, por el desarrollo de los medios masivos de comunicación, de la cibernética aplicada a las imágenes, pero principalmente porque el mundo moderno de fines de siglo y de milenio presenta formas de producción y reproducción semióticas en donde lo visual adquiere cada vez una mayor importancia (Haidar, 1995, p.8)

Es decir, las diversas formas corporales se encuentran contenidas en dicha complejidad, formando parte del sistema en forma liminal pero nunca quedan totalmente excluidas, están ahí veladas, ignoradas, pero jamás borradas, forman parte de la historia, de las culturas y de las sociedades. La vida se propaga porque el azar la ha dotado de multiplicación, existen mutaciones genéticas, sin embargo; entre más fuerte es la desviación más minoritaria y provisional resulta, este desorden azaroso crea, recrea y modifica nuevas formas y organismos; hay que asumir que la restricción y el azar (libertad) no está subordinado a ningún principio. Esto nos lleva al tema central:

¿Qué es lo normal y lo anormal? Canguilhem, hace una diferenciación entre anomalía y anormal, la primera se ha convertido en un concepto normativo y el segundo en un concepto descriptivo. Dicho autor menciona que la anomalía es un hecho biológico y tiene que ser tratado como hecho, es decir que la ciencia natural tiene que explicarlo y no apreciarlo:

La palabra anomalía, poco diferente de la palabra irregularidad, no debe ser tomada nunca en el sentido que se deduciría literalmente de su composición etimológica. No existen formaciones orgánicas que no estén sometidas a leyes; y la palabra desorden, tomada en su verdadero sentido, no podría ser aplicada a ninguna de las producciones de la naturaleza (Canguilheim, 2005, p. 97).

En este caso cabe mencionar que toda anomalía no es patológica como menciona Canguilhem, pero únicamente la existencia de anomalías patológicas ha susci- 
tado una ciencia especial de las anomalías que tiende normalmente, por el hecho de que es ciencia, a expulsar de la definición de la anomalía toda huella de noción normativa.

Cuando se habla de anomalías no se piensa en las desviaciones estadísticas que constituyen las simples variedades, sino que se piensa en las deformidades perjudiciales o incluso incompatibles con la vida, refiriéndose a la forma viviente o al comportamiento del ser vivo no como un hecho estadístico sino como un tipo normativo de vida, en donde está presente la organización -orden (Canguilhem, 2005, p. 101).

Así pues, la diversidad no es la enfermedad, lo anómalo no es patológico. La anormalidad se hace patente en la multiplicidad espacial, la enfermedad se hace patente en la sucesión cronológica y desde el momento en que la etiología y la patología de una anomalía son conocidas, lo anómalo se convierte en patológico (Canguilhem, 2005, p. 103).

Lo propio de la enfermedad consiste en interrumpir un curso de vida, cuando se vuelve crónica existe un "antes" que el paciente y/o su círculo recuerdan con nostalgia. Por lo tanto, no se está enfermo en relación a los otros, sino también con relación a uno mismo.

Este fenómeno se puede observar en el caso de la acromegalia, enfermedad que se presenta después de la edad adulta, la nostalgia del otro "yo" se hace presente de ahí en adelante en el espejo y en el cuerpo encarnado ahora modificado, deformado e irreconocible. Dentro del desorden corporal y hormonal, el cuerpo se regresa a una extraña homeostasis para continuar con la vida, el caos como una desintegración organizadora.

Lo propio de la anomalía consiste en ser constitucional, congénita, incluso cuando la aparición se atrasa con res- pecto al nacimiento y solo es contemporánea del ejercicio de la función; por lo tanto, quien lleva una anomalía no puede ser comparado con sí mismo, no existe un antes y un después como en la enfermedad. Este es el caso que se presenta en la acondroplasia.

La forma de integrarlos es a partir del discurso de la inclusión y la no discriminación, sin embargo; esto pareciera que solo resalta su condición sin integrarlos realmente en el sistema global, sino que continúan en la infraestructura. El autor recomienda complejizar nuestros sistemas de explicación de los sistemas. La idea de sistema no es solamente armonía, funcionalidad, síntesis superior, lleva en sí, necesariamente, la disonancia, la oposición, el antagonismo; por lo tanto, no hay organización sin anti organización (Morin, 1977, pp.130-131).

A pesar de que ambas condiciones son causadas por circunstancias diferentes comparten características corporales peculiares que sobresalen de la población estándar. Para la presente investigación se integran los aspectos semióticos que se consideran "anormales", para ello se analizarán e integrarán datos obtenidos en investigaciones previas para conocer la construcción identitaria de dicha diversidad corporal desde la experiencia de los grupos de estudio, partiendo del análisis semiótico-discursivo como herramienta metodológica, dicho análisis permitirá una aproximación de cómo se da esta construcción.

Para conocer esta construcción se partirá del análisis del discurso, el papel que cumple el lenguaje es una guía para la realidad social. El simbolismo lingüístico proporciona elementos significativos para entender una sociedad, producto de una serie de significados y valores que le otorgamos a las palabras para crear cultura. Podemos decir qué esta última es generadora de un sistema de símbolos y significados compartidos por los miembros de un grupo. 


\section{Acondroplasia Aplicación de semiótica visual}

Yoyito y Yoyita: un Gran Matrimonıo de Pequeños Artistas del Circo

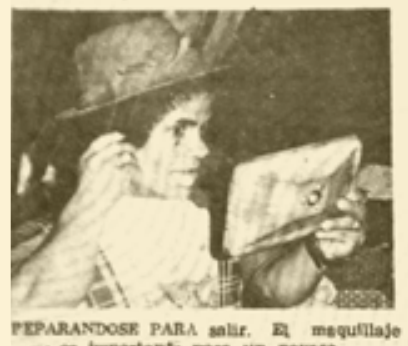

a importanto pari un paraso.

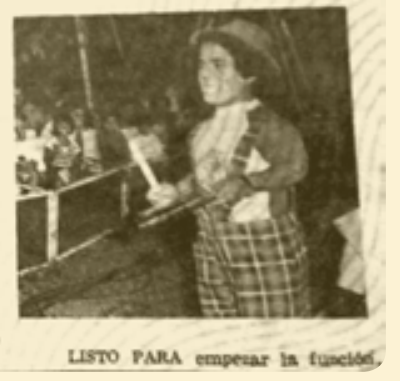

Imagen 1. Fotografía tomada de la original. Fuente: proporcionada por uno de los informantes (23 de abril de 2014).

\section{Roland Barthes, El mensaje fotográfico}

\section{Los procedimientos de connotación}

La fotografía fue recortada de un periódico y se colocó en el álbum familiar para el recuerdo de sus días de éxito como payasos de circo.

\section{Trucaje}

2. Pose

- La nota periodística se enfoca solo en el personaje de sexo masculino, en el texto se menciona a su esposa Yoyita pero no está presente en la fotografía. De acuerdo con Perea es una fotografía de reportaje. Considero que fue una escena preparada para resaltar el momento previo a la función.

\section{Objetos}

- El objeto principal de la foto de lado izquierdo es un espejo improvisado que Yoyito usa para maquillarse, parece un espejo retrovisor o lateral de un automóvil. Se ven artefactos detrás de Yoyito por lo que no es un camerino en sí.
- El objeto principal de la foto del lado derecho son unos golos para hacer malabares como parte de su espectáculo, la cerca de madera que separa al público del artista, unos cables en el piso y se ven los tubos o postes que sostienen la carpa del circo.

4. Esteticismo. La parte estética en este par de imágenes quizá este en los personajes mismos, en los maquillajes y en la alusión a actores de las artes circenses, pero hablando propiamente de la fotografía, lo estético está en la composición, el encuadre y la perspectiva del fotógrafo.

- Las tomas en ambas fotos, el acercamiento para resaltar el maquillaje y el momento que iniciara el espectáculo.

\section{Sintaxis}

- En este caso en las fotos se muestra una secuencia antes de salir al escenario y cuando va a dar inicio. Yoyito ultima detalles antes de salir a la platea y después se prepara para dar inicio al espectáculo, el público lo observa atento.

\section{Denotación}

El texto nos habla de un matrimonio de pequeños artistas que trabajan en el circo de payasos; sin embargo, agregan el adjetivo GRAN para enfatizar su estatura, se muestra como se prepara con profesionalismo para la función. Resalta la ausencia de Yoyita en la fotografía, otorgándole más peso a la presencia de Yoyito.

\section{Connotación}

El enano como diversión, objeto de burla por su condición está limitado a solo desempeñarse como payaso o bufón, insertado en el imaginario social desde tiempo remotos. Por lo tanto, solo puede trabajar en un circo, el estereotipo de la gente pequeña, se relaciona con la risa, la mofa, divertir a los otros por medio de la apariencia física. La mención de que sea un matrimonio de enanos, genera curiosidad y asombro a los lectores y hace más espectacular la nota. 


\section{Umberto Eco \\ La estructura ausente}

1) Nivel icónico (I)

- Ambiente

Al interior de un camerino, y una carpa de circo, poca luz

2) Nivel icónico (II)

- Personajes

Yoyito: Persona del sexo masculino de talla baja, joven, maquillándose para su puesta en escena, trae puesto un sombrero, un jumper a cuadros y playera de manga, porta un anillo grande en la mano derecha, y otro en la mano izquierda y un reloj en la muñeca, toma un espejo con la mano izquierda. A pesar de que en el texto se menciona a su esposa Yoyita, ella no aparece en las imágenes. Público de fondo posando su mirada en el personaje Yoyito.

3) Nivel iconográfico (I)

- Ambiente

Ambiente circense, dentro del camerino y en la platea con público presente.

\section{4) Nivel iconográfico (II)}

- Personajes

La actividad de Yoyito es de payaso de circo, junto a su esposa.

5) Nivel tropológico

- Los personajes fuera de la norma generan expectativa y morbo en los medios de comunicación, se resalta en el texto que es un matrimonio de personas pequeñas.

6) Nivel tópico

- Circo- diversión

- Circo-enanos

- Circo-payasos

- Circo-risas

7) Nivel entimémico

Ser enano significa trabajar en un circo, divertir a los demás a partir de su apariencia, se agrega un disfraz para mayor "diversión".

\section{Aplicación del Análisis del discurso Pêcheux (Formaciones imaginarias)}

1. Formación socio-histórico-cultural-política

El discurso se pronuncia siempre desde condiciones de producción dadas, desde determinado lugar en una formación social; del mismo modo, los sujetos del discurso están situados al interior de una relación de fuerzas que existe entre los elementos antagónicos de un campo político dado. El lugar desde donde se produce el discurso es el que determina el valor de lo que se dice, se promete o se denuncia; en este sentido, la misma declaración puede ser un arma terrible, o una comedia ridícula (Pêcheux en Haidar, 2006, p. 213).

\section{Narrativa 1}

(...) Mucha gente tiene esa mentalidad de "Oye ¿y por qué te hiciste chiquita? ¿Por qué estás enanita?" Porque así me hizo Dios "No, no, no Dios no te hizo", ¿entonces? "¿Cargaste mucho? ¿Cargabas a tus hermanos? o ¿Qué te pasó?" Cuando empiezan así, iahí nos vemos! Una ocasión hace años "¿Oye tú no eres de aquí verdad?" si soy de aquí de México, "No" ¿Entonces? "Tú eres de otro planeta" iChingas a tu madre! Estaba aquí mismo en la ciudad con un cuate, le digo no manches "¿entonces por qué no hay muchos enanos?" Si hay, pero todos están escondidos debajo de la cama... son muchos los que no quieren salir (...). (Sam, 59 años $)^{6}$

\section{Narrativa 2}

(...) Ven a un chaparrito o un Síndrome de Down y iUy! muchos creen que son monstruos, muchos creen que son contagiosos "no los toquen" o "iay que chistoso!" pero son las mentes, muchos niños están acostumbrados a "ándale enano", "ven enano" y cuando lo ven a uno se desconciertan, les da miedo, pero por lo que les dicen, a la gente pequeña la relacionan con los duendes, con los brujos, con los esos fetiches de la brujería (muñecos vudú) ¿Por qué? Por lo chiquito, que pasa con Maussan

6 Entrevistas, 2013-2014, en el D.F. y zona metropolitana. 
y todos esos, el ese programa del 13, Extranormal "iAy vi una gente chiquita, que son así!” (...). (Ned, 51 años).

Para Goffman existe una identidad social virtual que refiere al carácter que le atribuimos al individuo debería considerarse como una imputación hecha con una mirada retrospectiva en potencia, y la identidad social real, es la categoría y los atributos que, de hecho, según pueden demostrarse, y que le pertenecen (Goffman, 2006, p.12).

Esto resalta a través de la historia de las personas de talla baja, han sido consideradas de diversas formas. En Egipto debido a su asociación con las deidades Bes y Ptah, se les asignaba labores importantes como sacerdotes, joyeros, cuidadores de blancos o enfermeros. No obstante, es en la Grecia antigua donde encontramos los primeros ejemplos de prejuicios en contra de estos individuos. No es que los griegos fuesen una sociedad discriminatoria de las anomalías físicas. Como señala Marta L. Edwards (1997), los griegos no habían alcanzado un nivel de abstracción para percibir una categoría de discapacidad física; las personas a priori se les prohibía el desempeño de ciertas actividades esperando cumplir otras. Aquellos que manifestaban las discapacidades más severas eran integrados a comunidades que los acomodaban según sus habilidades (Edwards en González, 2014).

En los períodos siguientes de la Historia, el papel primordial de las personas de talla pequeña fue la de entretener y divertir en las cortes. En Roma, por ejemplo, eran utilizados para satisfacer el apetito de la realeza en cuanto a violencia y lujuria. Así, durante la época de Domiciano, estos eran obligados a combatir entre ellos o en contra de las amazonas. Otros participaban en juegos eróticos con Julia, la hija de Augusto, siempre curiosa de nuevas experiencias (Adelson, 2005).

El asunto no era diferente en el lejano Oriente, donde también eran sujetos de explotación, como en la corte de Hsuan Tsung, quien creó un harem llamado el "Lugar de Descanso para Monstruos Deseables", donde concentraba a varios "enanos". Durante el Renacimiento, las conductas hacia las personas de baja estatura cambiaron, dejaron de ser utilizados en formas crueles para convertirse en sujetos singulares e inapreciables, meras curiosidades que servían como deleite en la corte.

En España las personas de talla baja eran muy importantes dentro de la familia real, aunque eran ocultados. Los "enanos", aparte de que algunos eran ingeniosos y emparejaban con los hombres de placer, divertían por su simple presencia, por su pequeñez. Con el declive de las cortes, para el siglo XVIII los "enanos" comenzaron a ser exhibidos de manera frecuente en ferias, carnavales y tabernas. Muchos "enanos" de la corte tuvieron que exhibirse públicamente con la intención de asegurar su subsistencia a finales del siglo XVIII (González, 2014).

Muy pocas personas de baja estatura alcanzaron el éxito que tuvieron otros personajes de talla baja. Pero eso no significaba que estuviesen contentos con su condición. Lavinia escribió al respecto en sus memorias nunca publicadas: "Si la naturaleza me otorgó con algún otro gran atractivo personal, éste era relativamente pequeño comparado con la inconveniencia, dificultad y molestia que vivo por ser de estatura diminuta" (Nickell, 2005, p.118).

Sin embargo, en los carnavales de la época eran exhibidos comúnmente con la consigna siempre de ser "La persona más pequeña del mundo", a menudo presentados al lado de los gigantes del circo para resaltar de esta manera su pequeñez. Considerados hoy día un espectáculo degradante, estas ferias de "fenómenos" en Estados Unidos fueron responsables también de popularizar la palabra midget -que por su asociación con estos espectáculos- es considerada ofensiva para referirse a las personas de baja estatura. Aunque este tipo de espectáculos cayeron en desuso en los inicios del 
siglo XX, existe un remanente de estos, pues conservan cierta popularidad incluso hasta nuestros días: Las villas de enanos. Surgiendo como un derivado de las compañías exclusivamente formadas por "enanos", son lugares recreativos en donde se presenta de manera idílica una comunidad de personas de talla baja viviendo en pequeñas casitas para entretenimiento de la gente de estatura estándar (González, 2014).

Representados desde el arte, la fotografía, el espectáculo, cine y varios ámbitos la gente pequeña ha estado presente, a lo largo de la historia, resaltando sus características peculiares o a partir de un enfoque alternativo de belleza en el arte contemporáneo buscando la inclusión.

El uso de la palabra enano a través de distintas etapas de la Historia universal, narra las diferentes connotaciones sociales y culturales de ese concepto. En la terminología médica la palabra enano solo es una descripción que hace referencia a una característica generada por una alteración genética o una enfermedad. Sin embargo, cuando revisamos todo el contexto del término, nos damos cuenta que a lo largo del tiempo se ha resignificado de acuerdo a las normas, costumbres e ideologías; gestando discriminación y estigma hacia el otro, acentuándose con el uso "políticamente correcto" de las palabras, ya que al prohibirlas o resaltarlas potencializa su negatividad y por ende su exclusión social.

\section{Tipología de la imagen: Fotografía artística}

Contexto: No se encontró, solo este comentario de la artista:

De la fotografía Gigante..., Arbus escribió: "Cuando las mujeres están en cinta suelen tener pesadillas, suelen soñar que su bebé es un monstruo. Creo que conseguí captar esa expresión en la cara de la madre cuando contempla a Eddie y piensa, "Oh iDios, no!".

\section{Descripción}

La fotografía es a blanco y negro, profundidad de campo (nitidez de todos los planos) y uso de flash, tiene una perspectiva desde un plano bajo para resaltar la altura del muchacho, se realizó la composición enfatizando la altura por medio del contraste con sus padres, colocados en un plano posterior para que se vieran aún más pequeños con respecto a Eddie. La fotógrafa argumenta que consiguió captar la expresión de la madre, sin embargo, no aclara si "captó" un momento espontáneo o captó un momento que ella misma fabricó.

La posición del padre es la clásica postura del científico observando al monstruo, a distancia con las manos en los bolsillos de la bata. Mientras la madre se interpone entre ellos con las manos sobre su cadera, levantando la cabeza para observar a su hijo. Eddie usa sus dos bastones para mantenerse de pie, encorvado mira hacia abajo en la dirección donde se encuentran sus padres.

\section{Acromegalia \\ Aplicación de semiótica visual}

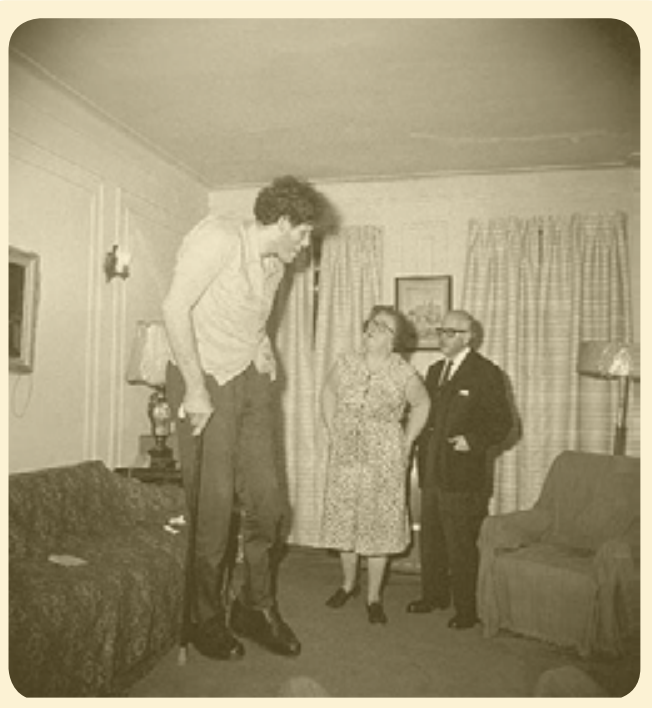

Imagen 2. Un gigante judío, en su casa, con sus padres en el Bronx. (Nueva York, 1970). Estate of Diane Arbus, LLC. 


\section{Lotman \\ - El ensemble artístico como espacio de la vida cotidiana}

La organización del [interior], no solo la distribución de los muebles, adornos, cuadros y esculturas dentro de un local dado, no solo la conformación artística de las paredes, el cielo raso y el piso. Al hablar del ensemble interior, es oportuno subrayar otra particularidad: en el contexto de su ensemble natural la obra de arte está en la vecindad no solo de obras de otros géneros, sino también de obras de otras épocas. Cualquiera que sea el interior cultural realmente existente que escojamos, nunca se llena de cosas y obras sincrónicas por su momento de creación (Lotman, 2000, p.114).

Los interiores compuestos exclusivamente de objetos sincrónicos y de un solo estilo, producen una impresión triste porque están compuestos de objetos cuya unidad de estilo y sincronicidad cronológica están demasiado manifiestas. Esto se hace particularmente perceptible cuando algún modelo de interior es copiado con exactitud en el mobiliario de un local real, esto es, cuando al precio de grandes pérdidas tiene lugar una sustitución simultánea de todos los objetos del interior (la cosa es que en toda "composición modelo" es cierto el lenguaje, pero cuando la convierten en un interior real, es utilizada como texto. En el primer caso esto no es más que la posibilidad de decir algo; en el segundo, un mensaje real (Lotman, 2000, p.116).

Diane Arbus, creo todo su escenario para dar el efecto deseado: El Gigante como amenaza para sus padres, algo incontrolable desde su gestación hasta la actualidad.

La autora agrega en su comentario el prejuicio del monstruo no deseado; sin embargo, la madre siempre tendrá que lidiar con él, ella lo trajo al mundo.

\section{Imagen compleja}

\section{- La escena metafórica}

Para Catalá, en el origen de toda metáfora hay un componente emotivo de la realidad percibida o imaginada: sorpresa, admiración, piedad, animadversión, entre otros. Es decir, hay una valoración subjetiva de la realidad objetiva, es esta introspección la que se quiere transmitir. De esa urgencia por comunicar una experiencia subjetiva, es decir, por objetivar esa experiencia, nace la forma metafórica.

Pero una vez creada, esta forma se autonomiza, ya sea porque crea, en el caso de la metáfora verbal, un neologismo que acaba, con el tiempo, por designar una realidad desprovista de emoción (podríamos decir que, en este caso, la realidad se amolda a la metáfora) o porque, como sucede en el caso de la imagen metafórica, la forma sigue siendo capaz de crear emociones, aunque estas no tengan ninguna conexión con la original (Catalá, 2005, p. 406).

La fotografía de Diane Arbus resalta la metáfora del gigante en su composición fotográfica, la acromegalia genera crecimiento desmedido, sin embargo, la artista lo enfatiza, creando la atmosfera adecuada en ese cuarto.

\section{Aplicación del Análisis del discurso Pêcheux (Formaciones imaginarias)} 1. Formación socio-histórico-cultural-política

Como se observó en el ejemplo de acondroplasia, Haidar profundiza en los planteamientos del autor y afirma que los sujetos semiótico-discursivos son multidimensionales, están interpelados por ideologías heterogéneas, lo que conlleva a que las formaciones imaginarias no solo sean heterogéneas sino contradictorias porque derivan de las formaciones ideológicas y discursivas que son constitutivas de la subjetividad (Haidar, 2006, p. 216). 


\section{Narrativa 1}

...Pero no las manos siguieron así, diferentes, no grandes como las tengo ahorita pero si ya diferentes, yo era de facciones de todo muy finito, muy delgadita, bueno pues ya después de tener hijos, todavía le regale ropa a mi nieta, ropa que yo usaba y le digo: un día me vi, dije hay que chistoso, me amaneció hinchada mi nariz, vivía mi mamita que en paz descanse y hablando por teléfono, le digo "mami ¿Qué crees?", le digo que me está creciendo la nariz y las manos, le digo quien sabe por qué, "Ay mijita ni te alarmes, mira cuando uno se está haciendo viejo, eso pasa", tenía yo 32 años, la edad de mi nieta y dije bueno pues si ya me estoy haciendo vieja, lo acepté, ya no le di importancia, ieh! me toman una foto en un evento deportivo en la escuela y me veo y le digo a mi secretaria "Ay Lulú mira, que fea salí, le digo te fijas que narizota tan fea me sacaron, no pues la nariz se me estaba hinchando". No me afligía, lo notaba yo, lo registraba, vamos lo registraba, decía yo "iQue me importa!" o sea que yo solita me platicaba, me hablaba y me decía yo, "Mira Lulú como te pusiste bien fea, (chasquea los dientes) pero eso no importa", ya, me distraía (Lulú, 74 años).

\section{Narrativa 2}

Yo soy la más chica de mis hermanas, somos 6 y me decían que yo era la mayor, ¿cómo crees que estaría? estaba aparte toda hinchada, toda deforme, mira esto (la cara y el cuello) negro, negro pero así y así sumido (los ojos) me decían "hija arréglate, sal" en verdad no quiero arreglarme, no me importa yo lo que quiero es sentirme bien, a mí que me importa arreglarme, hacer quehacer, yo no quería hacer comida, ay no, no ifue horrible iFue horrible! ¡Ay sí! Yo me sentía fea, yo cuando la primera cirugía que me hicieron, este pedí un espejo a mi hermana, tráeme un espejo, ¡Ay no, me traumé! Le decía iesta no soy yo, este es un monstruo! Le decía iSoy un monstruo"! ¡Yo no soy así! mi cambio, si les decía "No soy yo", ve ni mi propia hermana me reconocía (Cachito, 47 años).

\section{Antecedentes históricos}

Los antecedentes históricos de acromegalia están sujetos a una interpretación muy probablemente equívoca, informada sobre todo por las representaciones realizadas por las artistas de la época, que nos hacen pensar en la presencia de la acromegalia sin que haya una prueba concluyente que lo demuestre, ya que, durante el curso de la historia, esta condición ha sido relacionada con gigantes, monstruos y ogros.

Para mediados y fines del siglo XIX la popularidad de espectáculos itinerantes - como los circos - se incrementó, convirtiéndose en una forma de entretenimiento más; siendo un escaparate para muchos gigantes que no necesariamente padecían acromegalia. Durante el siglo pasado encontramos una gran lista de personajes famosos con acromegalia. En el medio cinematográfico, deportistas o los luchadores profesionales. Caso curioso el de la lucha libre, ya que este deporte-espectáculo también ha servido como un medio en el cual muchos acromegálicos terminan desempeñándose debido a sus características físicas.

Las dos entrevistadas describieron cómo percibieron los cambios en su cuerpo, lo cual las hacía sentirse mal con su aspecto, Cachito decía incluso no reconocerse a sí misma y resignificarse como un monstruo. Por otro lado, Lulú también comenzó a notar cambios, y se dio cuenta que sus rasgos faciales antes eran diferentes, ahora ella dice "soy más tosca y más gorda", esto ha propiciado que se subestime y se sienta fea. Este testimonio nos muestra cómo dentro del estereotipo de lo bello en Occidente, los sujetos introducen en lo bello las facciones finas, en cuerpos delgados; y lo tosco, lo burdo y lo gordo, entren en los parámetros de lo abyecto y lo antiestético.

\section{Conclusiones}

Dentro de la investigación sobre el contexto histórico de cada una de las imágenes, encontré interpretaciones 
donde se desconocía el origen de la imagen. El contexto se encuentra dentro del discurso de la imagen, nos dice las condiciones de producción y recepción, y, por lo tanto, la interpretación desde la visión del creador pero... ¿Qué sucede si se desconoce el contexto e interpreto desde mi horizonte? ¿Qué tan alejado puedo estar de la realidad? La realidad que existe dentro de la imagen y desde donde fue creada. Desde la perspectiva de Barthes, toda fotografía es un mensaje que tiene una fuente emisora, un medio por el que se difunde y un público receptor. Una misma foto cambia de significado cuando pasa de un medio a otro, dependiendo también de quién la emite y de quién la recibe.

En el caso de las imágenes utilizadas en este trabajo, existe un contraste en cuestión de condiciones médicas; sin embargo, ambas han servido a lo largo del tiempo para resaltar las diferencias corporales ante el espectador, que capta estas imágenes en un instante, o de manera contemplativa, los ojos nos crean una realidad, mientras la conciencia y la imagen corporal está construida desde varias miradas, incluyendo la de los otros, el otro yo emerge de una fotografía, de una pintura, de un autorretrato, el doble malvado, el otro que se esconde, el otro yo real, la imagen juega el papel del gemelo hologramático, que muestra la profundidad y el movimiento desde la percepción.

En la imagen la mirada es un componente más que vehicula una subjetividad a través de un organismo compuesto por distintos elementos, algunos de ellos objetivos y otros subjetivos. La única forma de comprender este tipo de hibridaciones y su importancia es examinar con atención las imágenes y describir el vocabulario de sus formas. La imagen y la visión se equiparán en ese espacio imaginario, unas veces virtual, otras representando, en el que se funden el observador y lo observado en un crispado contraste de fenomenologías (Catalá, 2005, p. 32).
La imagen nos lleva a diferentes épocas, nos introduce en una realidad alterna, no solo vemos a través de los ojos del autor de la obra. La noción de punto de vista sirve, en este sentido, de metáfora para comprender el entramado de relaciones de que se componen las imágenes, es decir; la imagen ya no existe, existen en todo caso las imágenes, siempre en plural.

\section{Referencias}

Aguado, J. C. (2004). Cuerpo humano e imagen corporal. Notas para una antropología de la corporeidad. México: Facultad de Medicina/ Instituto de investigaciones de la UNAM.

Barthes, R. (1976). “El mensaje fotográfico". En La Semiología. Buenos Aires: Editorial Tiempo Contemporáneo.

(1976). "Retórica de la imagen". En La Semiología. Buenos Aires: Editorial Tiempo Contemporáneo.

Barragán, A. (2011). “Las metáforas del cuerpo: entre la antropología simbólica y la Semiótica de la cultura". En Barragán, Anabella y González Quintero, Lauro (Coord.) La Complejidad de la Antropología Física (Tomo II). México: ENAH., (pp. 363-389).

Catalá, J. (2005). La imagen compleja: La fenomenología de las imágenes en la era de la cultura visual. Universidad Autónoma de Barcelona.

Eco, U. (1978). La estructura ausente. Barcelona: Editorial Lumen.

Canguilhem, G. (1971). Lo normal y lo patológico. México: Siglo XXI.

Geertz, C. (1992). La interpretación de las culturas. España: Gedisa.

Goffman, E. (2001). La representación de la persona en la vida cotidiana. Buenos Aires: Amorrortu.

Amorrortu.

(1986). Estigma. La identidad deteriorada. Buenos Aires:

González, L. (2014). ¿Del suelo a la cabeza o de la cabeza al cielo? Una aproximación antropofísica sobre la acondroplasia. Tesis de Maestría. México,ENAH.

(2012). Nadie me dijo iQué tan grande podría ser! Percepción y experiencia corporal en personas con acromegalia. Tesis de Licenciatura. México,ENAH. 
Haidar, J. (2006). Debate CEU-RECTORÍA. Torbellino Pasional de los argumentos. México: Universidad Nacional Autónoma de México.

Horton, W. (2006). Principales hitos en la investigación sobre acondroplasia. Am. J. Med. Genet; 140a.

Lizárraga, X. (2003). “De la inquietud a la disciplina: la antropología física". En X. Lizárraga y J. Mansilla (Coord.) Antropología física: disciplina plural. México: Instituto Nacional de Antropología e Historia., (pp. 25-64).

Lotman, I. (2000). La semiósfera III: Semiótica de las artes y de la cultura. Madrid: Cátedra.

Mier, R. (2009). Cuerpo, afecciones, juego pasional y acción simbólica. en Revista Antropología, Boletín Oficial del Instituto Nacional de
Antropología e Historia Reflexiones encarnadas. Antropología del cuerpo. Nueva Época, (septiembre-Diciembre), (87), pp. 11-21.

Morin, E. (1977). El Método I. La naturaleza de la naturaleza. (2001) (1ed.). Madrid: Cátedra.

Nicolescu, B. (1996). La transdisciplinariedad. Manifiesto. Multiversidad Mundo Real Edgar Morin, A.C.; México.

Perea, J. (2012). Los Géneros Fotográficos. [En línea] http:// blogs.enap.unam.mx/asignatura/ivonne_juarez/wp-content/ uploads/2012/02/LOS-GENEROS-FOTOGRAFICOS.pdf 


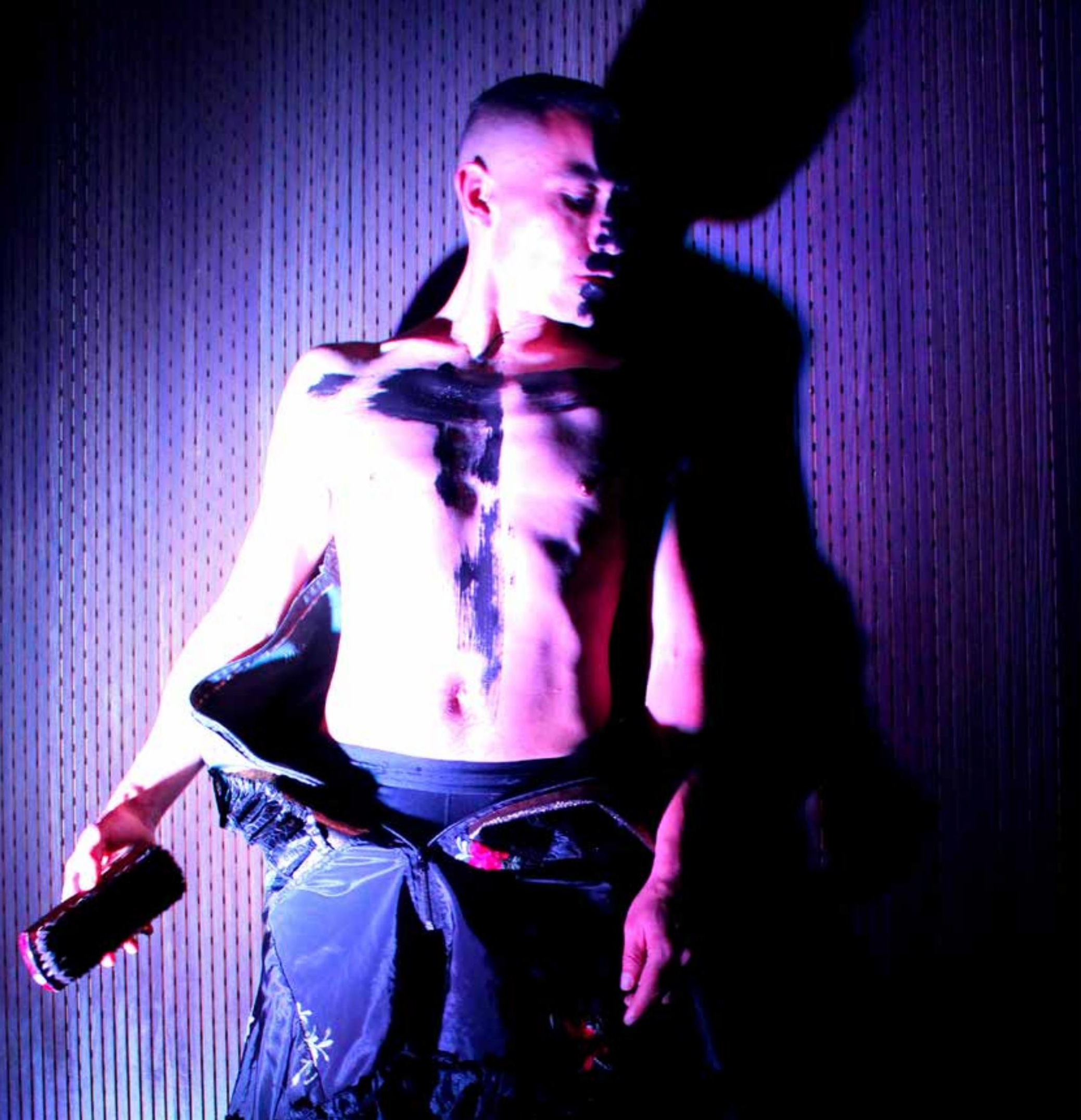

